\title{
The Effect of Multitasking and Grade Performance of Undergraduate Nursing Students
}

\author{
Lizy Mathew \\ Department of Nursing, The William Paterson University of New Jersey, Wayne, NJ, USA \\ Email: mathewl@wpunj.edu
}

Received 21 October 2015; accepted 5 November 2015; published 11 November 2015

Copyright (C) 2015 by author and OALib.

This work is licensed under the Creative Commons Attribution International License (CC BY). http://creativecommons.org/licenses/by/4.0/

(c) (i) Open Access

\begin{abstract}
The use of technology in social and educational settings has expanded over the last decade. Millennial students are more likely to multitask, using a variety of devices, in social and classroom activities. The aim of this study was to determine if in-class multitasking, specifically texting, had an impact on test scores of beginning nursing students. In this experimental study, ninety-one students enrolled in a first-level nursing course were randomly assigned to texting and non-texting groups during a class lecture. The students listened to a twenty-minute lecture on the concept of infection and a sexually transmitted disease. The texting group was asked to send three text messages to the instructor during the lecture. All students completed a ten-question quiz that pertained to the lecture content and two questions on demographics following the lecture. Most students who participated in the study were females and had a grade point average between 3.0 and 3.5. The results identified significant differences between the groups with lower scores in the texting group. One may conclude that multitasking during class affects outcomes in terms of grading.
\end{abstract}

\section{Keywords}

Multitasking, Grade Performance, Nursing Students

Subject Areas: Nursing

\section{Introduction}

The expansion of technology has created many challenges for educators of the current generation. Millennial learners develop critical thinking through experimentation, active participation, and multitasking with a variety of devices [1]. Multitasking has become common and students are often found to be using devices for social 
communication as well as learning during class. It has also become a common practice in academia and the outside world to commonly engage in using technological devices while attending classes and other events. Research has shown that distractions from multitasking can affect learning in students and may also result in poor grade performance [2] [3]. The interruptions and the multitasking of registered nurses while caring for patients have resulted in medication errors [4].

While there is evidence in literature suggesting negative effects on multitasking, there is a significant gap between nursing student grade performance and multitasking. It is crucial for the new generation of nurses to focus on optimal learning to be ready for the challenging world of healthcare. The purpose of this study was to examine whether multitasking during class affects grade performance among nursing students. An experiment was conducted using 91 nursing students who were enrolled in a first-level nursing course in a state university in the northeastern part of the United States. The students listened to a class lecture and completed a quiz following the lecture. Students were randomly assigned to the texting and non-texting groups from the lecture sections they attended. Students received instructions on texting the instructor during the lecture, which was considered multitasking. Students in the non-texting sections were asked to turn off and put away their electronic devices. The lecture was related to the concept of infection and specifically on the topic of a sexually transmitted disease. Students had no prior knowledge of the disease. The lecture lasted 20 minutes and the quiz consisted of ten multiple choice questions that pertained to the lecture content. The quiz grades were not part of the course grade as participation was voluntary and students were not required to participate in the study.

The results showed that significant differences in quiz grades existed between texting and non-texting students. Students in texting group scored significantly lower than students in the non-texting group. The results indicate that multitasking in a learning environment can significantly impact learning. The results of the study may be used by instructors and faculty in academia to make students aware that multitasking may affect grade performance and that texting and similar activities during class can impact students’ performance.

\section{Background}

Several theories discuss the negative impact of multitasking on learning. People who multitask are less likely to remember the information studied [5]. When multitasking, people are not doing two things at the same time but switching back and forth between tasks forcing the brain to neglect key information. This is a dangerous trend among nursing students to use technology while caring for patients where patient safety is crucial. Researchers who studied thinking of student nurses during a simulation activity found that students who did not focus on the task made errors during medication administration [6]. A study [7] found that multitasking resulted in a significant reduction in learning when the information was presented in verbal form to the learner. However, when the learner read the materials at his or her own pace, there was no notable reduction in learning. This study signifies the negative impact of multitasking in classroom learning where material is presented to the learners at a faster pace. Even though several studies point to the negative impact of multitasking and learning, there were no similar studies found in literature among nursing students in classrooms.

\section{Methodology}

\subsection{Design}

After obtaining institutional review board approval, the researcher developed a lecture, a packet which contained instructions and a quiz. The researcher also gained permission from a faculty member teaching a first level course of the undergraduate nursing program to conduct the study.

\subsection{Setting and Sample}

The convenience sample included students who were enrolled in a first nursing level course. Participants were volunteers who agreed to listen to the lecture and participate in the study. Students who were not willing to listen to the lecture, follow instructions and take the quiz at the end of the class were instructed to leave the classroom. The students who participated in the study were enrolled in the same course for three consecutive semesters. Students who repeated the course were asked to leave the classroom. Ninety-one students from a public state university from two cohorts participated in the study. Recommended sample size of 60 for each group was determined as appropriate for a power of 0.8 and moderate size effect of alpha $=0.05$ for a two sample t-test [8]. 
A majority of the participants were females between the age of 20 and 22. A majority of the participants also had a Grade Point Average between 3.0 and 3.5.

\subsection{Instrument}

The tool used was a post quiz consisting of ten questions specific to the lecture material presented and two questions pertaining to the sex and the current GPA of the participant.

Hypothesis

H0: There is no significant difference between the mean quiz scores of texting versus non-texting nursing students.

\subsection{Experimental Designs}

The study used an independent t-test to look at the mean difference in test scores between texting and non-texting students at the 0.05 alpha level. The intent of the research was to determine whether texting in class affected grade performance of students. To eliminate problems of prior knowledge, a standard lecture by the Centers for Disease Control and Prevention on antibiotic resistance was presented in class. This topic was new to the students at the first semester junior level and would only be covered during the second semester in pharmacology. After the lecture, the students were given 10 questions specific to the lecture to answer. The students were not told that they would be given a quiz at the end of the lecture.

In order to maximize randomization, separate instruction sheets were given to alternate rows of students where half the students in class were allowed to text and the other half were asked to turn off and put their electronic devices away. The texting group was asked to send three text messages to the instructor during the lecture. This confirmed that the students in the texting group were multitasking during the lecture. Students were also instructed not to talk to each other during the lecture and the quiz.

\section{Limitations}

The first limitation is that only students from one nursing program were included in this study. Another limitation is that the texting group of students could have been engaged in other forms of multitasking in addition to texting during the study. Quiz grades used in the study were not part of the course grade and could have impacted the results of the study. Differences in students' prior knowledge of the sexually transmitted disease could have also affected the results of the study. These limitations may limit the generalizations of the study.

\section{Results}

Table 1 shows the quiz scores and the results of texting (gr 1) versus non-texting (gr 2) with a significant lower score among the texting group. The null hypothesis states that there is no significant difference between the mean quiz scores of texting versus non-texting students with a similar standard deviation in both groups. The null hypothesis is rejected. Note that the p-value in Table 2 (Sig 2-tailed) is 0.000 , indicating that the hypothesis

Table 1. Group statistics.

\begin{tabular}{ccccc}
\hline Group & N & Mean & Std. Deviation & Std. Error Mean \\
Scores 1 & 47 & 5.19 & 1.296 & 0.189 \\
Scores 2 & 44 & 6.41 & 1.716 & 0.259 \\
\hline
\end{tabular}

Table 2. Independent samples test.

\begin{tabular}{|c|c|c|c|c|c|c|c|c|c|c|}
\hline & & & & \multicolumn{7}{|c|}{ t-test for Equality of Means } \\
\hline & & \multicolumn{2}{|c|}{$\begin{array}{c}\text { Levene's Test for } \\
\text { Equality of Variances }\end{array}$} & \multirow{2}{*}{$\mathrm{t}$} & \multirow{2}{*}{ df } & \multirow{2}{*}{$\begin{array}{l}\text { Sig. } \\
\text { (2-tailed) }\end{array}$} & \multirow{2}{*}{$\begin{array}{c}\text { Mean } \\
\text { Difference }\end{array}$} & \multirow{2}{*}{$\begin{array}{l}\text { Std. Error } \\
\text { Difference }\end{array}$} & \multicolumn{2}{|c|}{$\begin{array}{c}\text { 95\% Confidence Interva } \\
\text { of the Difference }\end{array}$} \\
\hline & & $\mathrm{F}$ & Sig & & & & & & Lower & Upper \\
\hline score & $\begin{array}{l}\text { Equal variances } \\
\text { assumed }\end{array}$ & 2.279 & 0.135 & -3.835 & 89 & 0.000 & -1.218 & 0.318 & -1.849 & -0.587 \\
\hline $\mathrm{S}$ & $\begin{array}{l}\text { Equal variances } \\
\text { not assumed }\end{array}$ & & & -3.800 & 79.891 & 0.000 & -1.218 & 0.320 & -1.855 & -0.580 \\
\hline
\end{tabular}


is rejected. The result noticeably indicates that multitasking in a learning environment may result in a lower grade performance among nursing students. The demographic data displayed that the male participants was made up of only $5 \%$ of the group studied. Therefore, this study did not look at the differences in male and female participants. The study also did not look at the effect of Grade Point Average (GPA) on the results as majority of the participants had a GPA between 3.0 and 3.5.

\section{Discussion}

The results of the study can be used by nursing instructors and nursing schools to inform the students of the negative impact of multitasking in class. While multitasking in class may affect grade performance, distractions such as texting while caring for patients may also cause errors in patient care. Errors in patient care can be detrimental to patient outcome and can even mean a difference in life and death for patients. This study affirms the results of the studies where interruptions and multitasking of registered nurses resulted in medication errors [4]; and students who were not focused on the tasks during a simulation activity made errors in medication administration [6]. This study also affirms that nursing students are similar to students in other fields of study where research shows that distractions from multitasking can affect learning and result in poor grade performance [2] [3]. From the results of this study, one may assume that multitasking can make students lose focus and that technology may only be used appropriately while caring for patients to avoid errors in patient care and to improve patient outcome.

\section{Conclusion}

The purpose of the study was to empirically examine whether multitasking in a classroom environment had an effect on grade performance of nursing students. The experiment was conducted by using 91 undergraduate nursing students enrolled in a first-level nursing class. The students were divided into texting and non-texting groups. The students participated in the class lecture, where one-half of the students (treatment group) sent text messages and the other half (control group) did not. The results of the study showed that test scores were significantly lower in the texting group compared to the non-texting group. The study concluded that multitasking among nursing students would result in poor grade performance.

\section{References}

[1] Montenery, S.M., Walker, M., Sorenson, E., Thompson, R., Kirklin, D., White, R. and Rose, C. (2013) Millenial Generation Student Nurses' Perceptions of the Impact of Multiple Technologies on Learning. Nursing Education Perspectives, 34, 405-409. http://dx.doi.org/10.5480/10-451

[2] Foerde, K., Knowlton, B.J. and Poldrack, A. (2006) Modulation of Competing Memory Systems by Distraction. Proceedings of the National Academy of Sciences of the United States of America, 103, 11778-11783. http://dx.doi.org/10.1073/pnas.0602659103

[3] Ellis, Y., Daniels, B. and Jauregui, A. (2010) The Effect of Multitasking on the Grade Performance of Business Students. Research in Higher Education Journal, 8, 1-10.

[4] Kalisch, B.J. and Aebersold, M. (2010) Interruptions and Multitasking in Nursing Care. Joint Commission Journal on Quality and Patient Safety, 36, 126-132.

[5] Dzubak, C. (2008) Multitasking: The Good, the Bad, and the Unknown. The Online Journal of the Association for the Tutoring Profession, 1. http://www.myatp.org/ejournal.htm

[6] Simones, J., Odland, D.N., Schug, V., Blazovich, L.M., Pivec, C., Daniels, J., Becker, M.K., Schulenberg, C., Lehman, S.M., Ohman, K.A., Swiggum, P. and Keller, P. (2014) Student Nurses’ Thinking during Medication Administration. Journal of Nursing Education and Practice, 4, 136. http://dx.doi.org/10.5430/jnep.v4n11p136

[7] Pashler, H., Kang, S.H.K. and Ip, R.Y. (2013) Does Multitasking Impair Studying? Depends on Timing. Applied Cognitive Psychology, 27, 593-599. http://dx.doi.org/10.1002/acp.2919

[8] Polit, D. and Beck, C.T. (2012) Nursing Research: Generating and Assessing Evidence for Nursing Practice. 7th Edition, Lippincott Williams and Wilkins, Philadelphia. 